\title{
Predictors of primary autograft cranioplasty survival and resorption after craniectomy
}

\author{
Tommi K. Korhonen, MBBS, ${ }^{1,2}$ Sami Tetri, MD, PhD, ${ }^{1,2}$ Jukka Huttunen, MD, PhD, ${ }^{3}$ \\ Antti Lindgren, MD, PhD, ${ }^{3}$ Jaakko M. Piitulainen, MD, PhD, ${ }^{4}$ Willy Serlo, MD, PhD, ${ }^{5}$ \\ Pekka K. Vallittu, DDS, PhD, ${ }^{6}$ and Jussi P. Posti, MD, PhD, ${ }^{6-8}$ on behalf of the Finnish National \\ Cranial Implant Registry (FiNCIR) study group
}

\begin{abstract}
${ }^{1}$ Department of Neurosurgery, Oulu University Hospital, Oulu; ${ }^{2}$ Research Unit of Clinical Neuroscience, Neurosurgery, Oulu University Hospital and University of Oulu; ${ }^{3}$ Neurosurgery of KUH NeuroCenter, Kuopio University Hospital, and Faculty of Health Sciences, School of Medicine, Institute of Clinical Medicine, University of Eastern Finland, Kuopio; ${ }^{4}$ Division of Surgery and Cancer Diseases, Department of Otorhinolaryngology-Head and Neck Surgery, Turku University Hospital, Turku Finland and University of Turku; ${ }^{5}$ PEDEGO Research Unit, University of Oulu, MRC Oulu, and Department of Children and Adolescents, Oulu University Hospital, Oulu; ${ }^{6}$ Department of Biomaterials Science, Institute of Dentistry, University of Turku and City of Turku, Welfare Division, Turku; ${ }^{7}$ Division of Clinical Neurosciences, Department of Neurosurgery, Turku University Hospital, Turku; and ${ }^{8}$ Department of Neurology, University of Turku, Finland
\end{abstract}

OBJECTIVE Craniectomy is a common neurosurgical procedure that reduces intracranial pressure, but survival necessitates cranioplasty at a later stage, after recovery from the primary insult. Complications such as infection and resorption of the autologous bone flap are common. The risk factors for complications and subsequent bone flap removal are unclear. The aim of this multicenter, retrospective study was to evaluate the factors affecting the outcome of primary autologous cranioplasty, with special emphasis on bone flap resorption.

METHODS The authors identified all patients who underwent primary autologous cranioplasty at 3 tertiary-level university hospitals between 2002 and 2015. Patients underwent follow-up until bone flap removal, death, or December 31, 2015.

RESULTS The cohort comprised 207 patients with a mean follow-up period of 3.7 years (SD 2.7 years). The overall complication rate was $39.6 \%$ (82/207), the bone flap removal rate was $19.3 \%(40 / 207)$, and 11 patients (5.3\%) died during the follow-up period. Smoking (OR $3.23,95 \% \mathrm{Cl} 1.50-6.95 ; \mathrm{p}=0.003$ ) and age younger than 45 years (OR 2.29, $95 \% \mathrm{Cl} 1.07-4.89 ; p=0.032$ ) were found to independently predict subsequent autograft removal, while age younger than 30 years was found to independently predict clinically relevant bone flap resorption $(\mathrm{OR} 4.59,95 \% \mathrm{Cl} 1.15-18.34 ; \mathrm{p}=$ 0.03 ). The interval between craniectomy and cranioplasty was not found to predict either bone flap removal or resorption

CONCLUSIONS In this large, multicenter cohort of patients with autologous cranioplasty, smoking and younger age predicted complications leading to bone flap removal. Very young age predicted bone flap resorption. The authors recommend that physicians extensively inform their patients of the pronounced risks of smoking before cranioplasty.

https://thejns.org/doi/abs/10.3171/2017.12.JNS172013

KEYWORDS autograft; bone resorption; cranioplasty; graft survival; postoperative complications

$\mathrm{E}$ LEVATED intracranial pressure (ICP) is a common neurosurgical emergency that may arise from several conditions, which cause an intracranial mass effect. ${ }^{1,9,34,35,46}$ In the case of conservatively refractory ICP elevation, the only viable treatment option is ICP-lower- ing surgery, i.e., decompressive craniectomy (DC), ${ }^{13}$ in which a large portion of the skull bone is removed and the dura mater opened, creating more room for the brain tissue to expand and thus reducing the $\mathrm{ICP}^{44}$ In our 3 centers, the bone flap removed in DC is customarily kept

ABBREVIATIONS BFR = bone flap resorption; $\mathrm{CP}=$ cranioplasty; $\mathrm{DC}=$ decompressive craniectomy; $\mathrm{DM}=$ diabetes mellitus; FiNCIR = Finnish National Cranial Implant Registry; ICP = intracranial pressure; $S S I=$ surgical site infection.

SUBMITTED August 14, 2017. ACCEPTED December 19, 2017.

INCLUDE WHEN CITING Published online May 11, 2018; DOI: 10.3171/2017.12.JNS172013. 
deep frozen at $-70^{\circ} \mathrm{C}$ until reimplantation during cranioplasty $(\mathrm{CP})$.

The cranium is repaired during $\mathrm{CP}$ by returning the previously removed autologous bone flap or by placing an artificial implant in the defect area. A successful CP will restore the contour of the cranium, protect the brain, and ensure a natural ICP, and some patients also show neurological improvement post-CP. ${ }^{5,6,11,38}$ Thus, CP has a great potential for improving the patient's quality of life. Although widely regarded as a routine operation, $\mathrm{CP}$ often involves serious complications, such as postoperative hemorrhages, surgical site infection (SSI), and, most importantly, resorption of the autologous bone flap. ${ }^{26,42,43}$

Bone flap resorption (BFR) implies weakening and loosening of the autologous bone flap after reimplantation and is regarded as a late CP complication involving nonunion of the bone flap with the surrounding bone margins and cavity formation in the flap itself, which eventually necessitates removal of the bone flap and a new CP using a synthetic implant. These additional operations increase costs and necessitate further hospital stays, while rendering the patient vulnerable to additional complications. The reported prevalence of BFR with autologous CPs in other settings approximately similar to ours has varied significantly, from $1.4 \%$ to $32.0 \%,{ }^{17,28}$ with infection rates ranging from $4.6 \%$ to $16.4 \% .4,4$

In order to carry out a comprehensive investigation into the predictors of $\mathrm{CP}$ outcomes, we established a nationwide Finnish National Cranial Implant Registry (FiNCIR), based on a consortium of 5 tertiary-level Finnish university hospitals with neurosurgical centers. These centers are responsible for all major calvarial reconstructive surgery in Finland and treatment of the associated complications. At present, the database contains data from 3 university hospitals covering a total of $481 \mathrm{CPs}$, and it is projected to cover all of Finland in the future. This paper is the first published work on the FiNCIR study and concentrates on evaluating predictors of outcome of autologous $\mathrm{CP}$ and BFR.

\section{Methods}

\section{Patients and Selection}

In this multicenter study, we identified all patients who had undergone $\mathrm{CP}$ at Oulu University Hospital and Turku University Hospital between January 1, 2002, and December 31, 2015, or at Kuopio University Hospital between January 1, 2005, and December 31, 2015. Of a total of 481 operations, we identified 207 primary autologous CPs, which compose the present cohort. Three autologous CPs were nonprimary and were therefore excluded. These 3 tertiary-level university hospitals serve separate districts with a total of 2,456,567 inhabitants as of December 31, 2015 , and are the only hospitals in which CP is performed in these districts. Thus, all patients with $\mathrm{CP}$ complications requiring neurosurgical interventions are also referred to these centers. Nonprimary CPs, minor CPs (e.g., small trepanation hole repairs), and CPs for craniosynostoses were excluded from the present material.

The study protocol was approved by the corresponding medical directors of all 3 hospitals. Additional eth- ics board approval was not required for this retrospective study in which data were extracted solely from patient databases, and patients were not contacted.

\section{Management of Elevated ICP}

Trauma patients who have an increased ICP greater than $20 \mathrm{~mm} \mathrm{Hg}$ regardless of conservative treatment are candidates for DC if a good neurological outcome can be expected. For stroke patients, the choice of surgical approach is based more subjectively on the patient's clinical condition, the findings on a CT scan, and the intraoperative decision of the surgeon. Some tumors may also require DC and subsequent CP. All 3 hospitals follow the international protocol for the treatment of elevated ICP.

At all centers, the standard protocol for therapeutic management of ICP aims to maintain an ICP of less than $20 \mathrm{~mm} \mathrm{Hg}$ and a cerebral perfusion pressure of greater than $60 \mathrm{~mm} \mathrm{Hg}$ by applying treatments in a stepwise scheme. All patients with a Glasgow Coma Scale score less than 8 undergo placement of an intraparenchymal ICP monitoring probe on a standard basis. If ICP remains more than $20 \mathrm{~mm} \mathrm{Hg}$ despite maximal medical therapy and insertion of a possible ventriculostomy, a large unilateral frontotemporoparietal DC (hemicraniectomy) or a bifrontal DC is performed based on the neurosurgeon's decision.

\section{Clinical Data}

Clinical data on patient characteristics, lifestyle, diabetes mellitus (DM), the etiology of the DC (i.e., primary diagnosis), the time interval between the $\mathrm{DC}$ and $\mathrm{CP}$ operations, complications, and possible implant removal were extracted from the hospital records. Complications recorded were BFR, deep and superficial SSIs, hematoma and seroma, CSF leak, unsatisfactory cosmesis, implant migration, hydrocephalus, and exposure of implant. All patients underwent one or more CPs, but only the primary autologous CPs were recorded here. Patients were considered obese if their BMI exceeded $30 \mathrm{~kg} / \mathrm{m}^{2}$, in accordance with the WHO criteria. ${ }^{49}$ Data on smoking and alcohol or other intoxicant abuse were also collected; a patient was considered to be a nonsmoker and nonabuser of intoxicants unless specifically mentioned as such in the hospital records. The size of the bone flap was determined from perioperative CT scans using the lateral 2D scout image. The CP groups with primary diagnoses of nontraumatic intracranial hemorrhage, intracranial ischemia, or nontraumatic subarachnoid hemorrhage were combined into a single stroke group. Data on the deaths of CP patients were acquired from Statistics Finland.

\section{Outcome Measures}

The primary end point was all-cause autologous bone flap removal. All patients underwent follow-up from the $\mathrm{CP}$ operation until bone flap removal, death, or December 31,2015 . The $\mathrm{CP}$ outcome was classified as autograft survival or all-cause bone flap removal as of the last followup date. A subgroup analysis was performed for patients with clinical BFR; outcomes were divided into nonresorbed bone flap versus $\mathrm{CP}$ removal or refixation due to BFR. The time from CP to BFR was calculated as the time 
TABLE 1. Characteristics and outcomes of 207 patients who underwent autologous CP

\begin{tabular}{|c|c|c|c|c|}
\hline Characteristic & Bone Flap Not Removed $(n=167)$ & Bone Flap Removed $(n=40)$ & Total $(n=207)$ & p Value \\
\hline Male, $\mathrm{n}(\%)$ & $100(59.9)$ & $28(70.0)$ & $128(61.8)$ & 0.24 \\
\hline Mean age in yrs (SD) & $43.2(16.3)$ & $37.4(14.1)$ & $42.1(16.0)$ & $0.04^{*}$ \\
\hline Age in yrs, $\mathrm{n}(\%)$ & & & & $0.02^{*}$ \\
\hline$<30$ & $33(19.8)$ & $13(32.5)$ & $46(22.2)$ & \\
\hline $30-50$ & $68(40.7)$ & $20(50.0)$ & $88(42.5)$ & \\
\hline$>50$ & $66(39.5)$ & $7(17.5)$ & $73(35.3)$ & \\
\hline Smoking, n (\%) & 27 (16.2) & $16(40.0)$ & $43(20.8)$ & $<0.001^{*}$ \\
\hline Intoxicant abuse, $\mathrm{n}(\%) \dagger$ & $27(16.2)$ & $10(25.0)$ & $37(17.9)$ & 0.19 \\
\hline $\mathrm{DM}, \mathrm{n}(\%)$ & $3(1.8)$ & $2(5.0)$ & $5(2.4)$ & 0.25 \\
\hline $\mathrm{BMI}>30, \mathrm{n} /$ valid cases ( $\%$ of valid cases) $\ddagger$ & $14 / 122(11.5)$ & $2 / 33(6.1)$ & $16 / 155(10.3)$ & 0.53 \\
\hline DC-CP interval in mos, $n(\%)$ & & & & 0.23 \\
\hline $0-3$ & $52(31.1)$ & $11(27.5)$ & $63(30.4)$ & \\
\hline $3-6$ & $48(28.7)$ & $17(42.5)$ & $65(31.4)$ & \\
\hline$>6$ & $67(40.1)$ & $12(30.0)$ & $79(38.2)$ & \\
\hline Primary diagnosis, $\mathrm{n}(\%)$ & & & & 0.37 \\
\hline Trauma & $58(34.7)$ & $19(47.5)$ & 77 (37.2) & \\
\hline Stroke & $92(55.1)$ & $19(47.5)$ & $111(53.6)$ & \\
\hline $\mathrm{ICH}$ & $15(9.0)$ & $2(5.0)$ & $17(8.2)$ & \\
\hline $\mathrm{ICl}$ & $55(32.9)$ & $10(25.0)$ & $65(31.4)$ & \\
\hline SAH & $22(13.2)$ & $7(17.5)$ & $29(14.0)$ & \\
\hline Benign tumor & $10(6.0)$ & $0(0.0)$ & $10(4.8)$ & \\
\hline Malignant tumor & $2(1.2)$ & $0(0.0)$ & $2(1.0)$ & \\
\hline Infection & $3(1.8)$ & $2(5.0)$ & $5(2.4)$ & \\
\hline Other & $2(1.2)$ & $0(0.0)$ & $2(1.0)$ & \\
\hline
\end{tabular}

DC-CP interval = time between DC and CP; ICH = intracranial hemorrhage; $\mathrm{ICl}=$ intracranial ischemia; $\mathrm{SAH}=$ subarachnoid hemorrhage.

${ }^{*} p<0.05$ for difference between normal recovery group and bone flap removal group.

$\dagger$ Includes abuse of alcohol and narcotics.

$\ddagger$ Values for 52 patients were missing.

between the $\mathrm{CP}$ and the head CT scan that confirmed the presence of BFR, except for one patient, whose BFR was discovered during a wound revision procedure, and so the date of CP removal was used instead of the CT scan date. The complications recorded were clinical BFR, deep and superficial SSI, hematoma, seroma, CSF leak, hydrocephalus, implant exposure, implant breakage, implant migration, and unsatisfactory cosmesis.

\section{Statistical Analysis}

All statistical analyses were performed using IBM SPSS (version 22, IBM Corp.). Categorical variables were first compared using Pearson's chi-square test or Fisher's exact test and the means of the continuous variables with ANOVA. Variables that were of clinical importance and/ or statistically significant in Pearson's chi-square test, Fisher's exact test, or ANOVA were chosen for further logistic regression analysis. Odds ratios and $95 \%$ confidence intervals of these variables were determined using binary logistic regression analysis with the enter method. Variables included in the logistic regression analyses were sex, smoking, intoxicant abuse, age, DM, and time interval between DC and CP (0-3 months, 3-6 months, or $>6$ months). Age was classified as either over/under the median (44 years) or $0-29,30-50$, or older than 50 years at the time of CP. The latter cutoff values were applied in order to facilitate interstudy comparison, as similar cutoffs have been used in previous publications. ${ }^{18,26,37}$

A 2-tailed $p$ value of $<0.05$ was considered statistically significant. Follow-up times, calculated as the time between the $\mathrm{CP}$ and removal of the bone flap, death, or December 31, 2015, are reported as the mean with SD. Likewise, time intervals between DC and CP are reported as mean with SD.

\section{Results \\ Descriptive Data}

The baseline characteristics and outcomes of the 207 autologous CP patients that we identified are shown in Tables 1 and 2. The mean follow-up time was 3.7 years (SD 2.7 years, range 2 days to 11.9 years). Stroke was the most common etiology of bone defect, accounting for 111 $(53.6 \%)$ cases, while 77 (37.2\%) defects had a traumatic etiology. The mean time interval between DC and CP was 184 days (SD 286 days), and a total of 82 (39.6\%) autologous CPs resulted in one or more complications, leading in 
TABLE 2. Characteristics and the prevalence of BFR in 207 patients who underwent autologous CP

\begin{tabular}{|c|c|c|c|c|}
\hline Characteristic & No Clinical BFR Detected $(n=188)$ & Clinical BFR $(n=19)$ & Total $(n=207)$ & $\mathrm{p}$ Value \\
\hline Male, n (\%) & $112(59.6)$ & $16(84.2)$ & $128(61.8)$ & $0.04^{*}$ \\
\hline Mean age in yrs (SD) & $42.9(15.8)$ & $33.5(16.3)$ & $42.1(16.0)$ & $0.02^{*}$ \\
\hline Age in yrs, $\mathrm{n}(\%)$ & & & & $0.02^{*}$ \\
\hline$<30$ & $37(19.7)$ & $9(47.4)$ & $46(22.2)$ & \\
\hline $30-50$ & 81 (43.1) & $7(36.8)$ & $88(42.5)$ & \\
\hline$>50$ & $70(37.2)$ & $3(15.8)$ & $73(35.3)$ & \\
\hline Mean bone flap size in $\mathrm{cm}^{2}(\mathrm{SD}) \dagger$ & $92.5(39.0)$ & $108.1(33.2)$ & $93.9(38.7)$ & 0.09 \\
\hline Smoking, n (\%) & $37(19.7)$ & $6(31.6)$ & $43(20.8)$ & 0.24 \\
\hline Intoxicant abuse, $\mathrm{n}(\%) \ddagger$ & $32(17.0)$ & $5(26.3)$ & $37(17.9)$ & 0.35 \\
\hline $\mathrm{DM}, \mathrm{n}(\%)$ & $5(2.7)$ & $0(0.0)$ & $5(2.4)$ & 0.99 \\
\hline BMI $>30, n /$ valid cases ( $\%$ of valid cases) $\S$ & $16 / 139(11.5)$ & $0 / 16(0.0)$ & 16/155 (10.3) & 0.38 \\
\hline DC-CP interval in mos, $\mathrm{n}(\%)$ & & & & $0.03^{*}$ \\
\hline $0-3$ & $55(29.3)$ & $8(42.1)$ & $63(30.4)$ & \\
\hline $3-6$ & $56(29.8)$ & $9(47.4)$ & $65(31.4)$ & \\
\hline$>6$ & $77(41.0)$ & $2(10.5)$ & $79(38.2)$ & \\
\hline Primary diagnosis, $\mathrm{n}(\%)$ & & & & 0.41 \\
\hline Trauma & $66(35.1)$ & $11(57.9)$ & $77(37.2)$ & \\
\hline Stroke & $104(55.3)$ & $7(36.8)$ & $111(53.6)$ & \\
\hline $\mathrm{ICH}$ & $17(9.0)$ & $0(0.0)$ & $17(8.2)$ & \\
\hline $\mathrm{ICl}$ & $61(32.4)$ & $4(21.1)$ & $65(31.4)$ & \\
\hline $\mathrm{SAH}$ & $26(13.8)$ & $3(15.8)$ & $29(14.0)$ & \\
\hline Benign tumor & $10(5.3)$ & $0(0.0)$ & $10(4.8)$ & \\
\hline Malignant tumor & $2(1.1)$ & $0(0.0)$ & $2(1.0)$ & \\
\hline Infection & $4(2.1)$ & $1(5.3)$ & $5(2.4)$ & \\
\hline Other & $2(1.1)$ & $0(0.0)$ & $2(1.0)$ & \\
\hline
\end{tabular}

$40(19.3 \%)$ cases to removal of the autograft. The mean 2D bone flap area was $93.9 \mathrm{~cm}^{2}\left(\mathrm{SD} 38.7 \mathrm{~cm}^{2}\right.$, range $9.2-322.0$ $\left.\mathrm{cm}^{2}\right)$. Twenty-three $(57.5 \%)$ of the graft removals occurred during the first 6 postoperative months, 1 (2.5\%) between 6 and 12 months, and $16(40.0 \%)$ occurred later than 12 months postoperatively. Eleven patients $(5.3 \%)$ had died during the follow-up period.

\section{Cranioplasty Outcomes: Normal Recovery Versus All-Cause Autograft Removal}

Postoperative complications and complications that required bone flap removal are listed in Table 3 . The results of the logistic regression analysis of the 40 cases in which the autograft was subsequently removed are shown in Table 4. Cigarette-smoking patients were more likely to undergo subsequent bone flap removal after CP than nonsmokers in a model adjusted for age, while in the same model an age less than 45 years at the time of $\mathrm{CP}$ was a risk factor for bone flap removal. In an interaction analysis, no significant impact of interaction between these 2 variables was observed (OR 0.54, 95\% CI 0.11-2.70; $\mathrm{p}=$ $0.45)$. Interestingly, smokers also had post-CP SSIs sig- nificantly more often than nonsmokers $(20.9 \%$ vs $7.3 \%, \mathrm{p}$ $=0.02$ ).

Patients with DM had a slight tendency for an increased risk of bone flap removal (40.0\% vs 18.8\%; OR 5.64, 95\% CI $0.81-39.38 ; \mathrm{p}=0.08)$ when adjusted for smoking, sex, and age (over/under the median), but statistical significance was not reached. When compared to all other etiologies and adjusted by smoking, sex, and age (over/under the median), neither trauma (OR 1.24, 95\% CI 0.57-2.69; $\mathrm{p}=0.59$ ) nor stroke (OR 0.91, 95\% CI 0.43-1.93; $\mathrm{p}=0.81$ ) had a significant impact on the CP outcome. Similarly, the timing of CP had no statistically significant impact on the outcome in a model adjusted for sex and age (Table 5).

\section{Subgroup Analyses: Bone Flap Survival Versus Bone Flap Resorption}

Nineteen (9.2\%) of the 207 autologous CPs developed clinical BFR, which necessitated implant refixation or removal at a later time. BFR occurred after a mean interval of 534.1 days (SD 397.4 days, range 103-1742 days). In a model adjusted for sex, patients younger than 30 years at the time of $\mathrm{CP}$ had a significantly higher risk of develop- 
TABLE 3. Postoperative complications and complications that required bone flap removal in 207 patients who underwent primary autologous $\mathrm{CP}$

\begin{tabular}{lcc}
\hline \multirow{2}{*}{ Complication } & \multicolumn{2}{c}{ No. of Patients (\%) } \\
\cline { 2 - 3 } & $\begin{array}{c}\text { Total } \\
(n=207)\end{array}$ & $\begin{array}{c}\text { Bone Flap Removed } \\
(\mathrm{n}=40)\end{array}$ \\
\hline BFR & $19(9.2)$ & $16(40.0)$ \\
\hline Deep SSI & $19(9.2)$ & $19(47.5)$ \\
\hline Hematoma or seroma & $18(8.7)$ & $2(5.0)$ \\
\hline CSF leak & $8(3.9)$ & $0(0.0)$ \\
\hline Unsatisfactory cosmesis & $7(3.4)$ & $1(2.5)$ \\
\hline Implant migration & $4(1.9)$ & $2(5.0)$ \\
\hline Hydrocephalus & $3(1.4)$ & $0(0.0)$ \\
\hline Exposure of implant & $2(1.0)$ & $0(0.0)$ \\
\hline Superficial SSI & $2(1.0)$ & $0(0.0)$ \\
\hline No complication & $125(60.4)$ & $0(0.0)$ \\
\hline
\end{tabular}

ing BFR than those older than 50 years (Table 6), and in the same model those 30-50 years at the time of CP were found to have a higher odds ratio for BFR than those older than 50 years, although the latter was not a statistically significant finding.

In the model adjusted for sex and age, a shorter time interval between DC and CP was found to be a risk factor for BFR (Table 5), although the correlation seemed to be very slight. Smoking had no significant effect on the development of BFR when adjusted for age over/under the median (OR 1.70, 95\% CI 0.60-4.84; $\mathrm{p}=0.32$ ), and the size of the bone defect was not found to predict subsequent BFR independently on adjustment for age (over/ under the median) and sex (OR 1.01, 95\% CI 1.00-1.02; p $=0.16)$. Compared to all other etiologies, stroke (OR 0.66, 95\% CI $0.23-1.83 ; \mathrm{p}=0.42)$ or trauma (OR $1.66,95 \%$ CI $0.59-4.62 ; \mathrm{p}=0.34$ ) did not have any significant effect on the development of BFR after adjustment for smoking, sex, and age (over/under the median). The 2D bone flap area was not found to have a statistically significant effect on BFR (Table 2).

\section{Discussion \\ Main Results}

The main finding in the present cohort of patients with autologous $\mathrm{CP}$ was that cigarette smoking is an independent predictor of a poor CP outcome, leading to autograft removal, while young age was found to be a risk factor for both CP removal and BFR. The time interval from DC to $\mathrm{CP}$ did not affect the risk of CP removal or BFR, and the primary diagnosis was not found to affect the $\mathrm{CP}$ outcome.

Most DC patients require long-term intensive care and are unable to smoke, but in our experience, many of them continue smoking after recovery from the primary insult, possibly compromising the $\mathrm{CP}$ outcome. The mechanism of smoking to the $\mathrm{CP}$ outcome is likely mediated by the vasoconstriction caused by nicotine ${ }^{41}$ and lowered tissue
TABLE 4. Predictors for autologous CP removal in $207 \mathrm{CP}$ patients obtained by logistic regression analysis (enter method)

\begin{tabular}{lll}
\hline \multicolumn{1}{c}{ Variable } & OR $(95 \% \mathrm{Cl})$ & $\mathrm{p}$ Value \\
\hline Age at cranioplasty $<45 \mathrm{yrs}$ & $2.29(1.07-4.89)$ & $0.03^{*}$ \\
\hline Smoking & $3.23(1.50-6.95)$ & $0.003^{*}$ \\
\hline The ORs of categorical variables represent comparisons with patients with no \\
risk factor. \\
${ }^{*} p<0.05$ for difference between normal recovery and implant removal groups.
\end{tabular}

oxygen, ${ }^{14}$ which, through surgical site oxygen deprivation, expose the patient to complications that possibly require bone flap removal. Indeed, we found that in our patient population, smokers had surgical site infections significantly more often than nonsmoking patients. Therefore, physicians should inform their patients of the pronounced risks of smoking before $\mathrm{CP}$.

The negative effect of smoking on the $\mathrm{CP}$ outcome is consistent with that found in existing reports on the association between smoking and adverse surgical outcomes in both neurosurgery ${ }^{20}$ and other surgical specialties. ${ }^{16,15}$ On the other hand, preoperative abstinence from smoking has been shown to provide protection from adverse surgical outcomes in numerous fields of surgery, ${ }^{19,23,27}$ and the prospect of major surgery may boost patients' motivation to cease smoking. ${ }^{39}$ It is possible, however, that even former smoking habits could have a negative effect on the CP outcome compared with complete abstinence from smoking.

Aseptic BFR is a late complication, and it has been well demonstrated that younger age increases the risk of BFR. ${ }^{7,12,18,26,33,36,37}$ Most skull growth takes place during the 1st year of life, but growth proceeds until the cranial vault is fully formed in adulthood. Cranial growth includes resorptive activity, and the preadolescent skull bone may be metabolically more active than the adult skull in this respect, which could play a part in the higher BFR prevalence observed in young patients.

We hypothesized that CPs performed later would be more susceptible to complications due to a longer storage time, as cryopreservation likely sacrifices the majority of the cells in the bone flap ${ }^{32}$ or renders them nonviable. ${ }^{2}$ Thus, the bone flap is considered a nonvital autologous scaffold, but it is hoped that it will integrate with the adjacent vital bone. In all 3 hospitals in this study, the bone flaps were deep frozen to $-70^{\circ} \mathrm{C}$ immediately after $\mathrm{DC}$ and thawed for $\mathrm{CP}$. We did not find any clear effect of $\mathrm{CP}$ timing on the outcome with this protocol. In keeping with this, a recent meta-analysis of 25 papers by Malcolm et al. ${ }^{25}$ concluded only that early any-material CPs were associated with increased odds ratios for hydrocephalus, and no association was found between $\mathrm{CP}$ timing and other complications, indicating that, regarding complications, the timing of $\mathrm{CP}$ might not be as important as previously hypothesized. The primary end point in the present study, however, was implant removal rather than any particular complication.

Although BFR resembles the physicochemical reaction of dissolution of bone matrix hydroxyapatite and enzymatic degradation of bone collagen, osteoclastic dissolution of the inorganic matrix of the bone flap should, in principle, 
TABLE 5. Effect of timing on autologous CP removal and BFR in 207 CP patients obtained by logistic regression analysis (enter method)

\begin{tabular}{|c|c|c|c|c|}
\hline \multirow[b]{2}{*}{ Variable } & \multicolumn{2}{|c|}{ Outcome } & \multicolumn{2}{|c|}{ BFR } \\
\hline & OR $(95 \% \mathrm{Cl})$ & $p$ Value & OR $(95 \% \mathrm{Cl})$ & $p$ Value \\
\hline Male sex & $1.19(0.54-2.64)$ & 0.66 & $2.84(0.75-10.71)$ & 0.12 \\
\hline \multicolumn{5}{|l|}{ Age at CP in yrs } \\
\hline$<30$ & $3.93(1.34-11.54)$ & $0.01^{*}$ & $4.03(0.96-16.95)$ & 0.06 \\
\hline $30-50$ & $2.99(1.17-7.65)$ & $0.02^{*}$ & $2.15(0.52-8.89)$ & 0.29 \\
\hline$>50$ & 1 & & 1 & \\
\hline \multicolumn{5}{|c|}{ DC-CP interval in mos } \\
\hline $0-3$ & $0.95(0.37-2.47)$ & 0.92 & $4.54(0.88-23.54)$ & 0.07 \\
\hline $3-6$ & $1.98(0.84-4.67)$ & 0.12 & $5.50(1.12-27.12)$ & $0.04^{*}$ \\
\hline$>6$ & 1 & & 1 & \\
\hline
\end{tabular}

The ORs of categorical variables represent comparisons with patients with no risk factor.

${ }^{*} p<0.05$ for difference between nonresorbed implant group and clinical bone flap resorption group.

increase the extracellular concentration of calcium ions, ${ }^{40}$ which should inhibit osteoclastic activity. 15,24 Therefore, the primary mechanism of BFR more likely resembles avascular necrosis rather than direct bone resorption by osteoclastic activity or enzymatic degradation of the collagenous matrix. Still, it remains unclear which factors result in clinically relevant BFR in CP patients.

Due to the known negative effects of DM on surgical outcomes $^{8,21,31,50}$ and the global increase in the prevalence of both type I and type II DM, ${ }^{30}$ the disease is likely to become an increasingly important variable in surgical decision-making in the future. We did not find a statistically significant association between DM and bone flap removal, but diabetic patients seemed to have a tendency for an increased risk of bone flap removal. The present sample size was nevertheless insufficient to clarify this matter definitively, since the cohort included only 5 diabetic patients, among whom the CP was removed in 2 cases.

Our findings suggest that the etiology of the ICP elevation (e.g., trauma, stroke) is not an important factor affecting bone flap survival. All of these etiologies cause brain damage, but only those with good recovery from the primary insult are selected for CP. This explains why no differences were observed between the primary diagnosis groups.

TABLE 6. Predictors of autologous CP resorption in $207 \mathrm{CP}$ patients obtained by logistic regression analysis (enter method)

\begin{tabular}{lcc}
\hline \multicolumn{1}{c}{ Variable } & OR $(95 \% \mathrm{Cl})$ & $\mathrm{p}$ Value \\
\hline Male sex & $2.84(0.78-10.36)$ & 0.12 \\
\hline Age at the time of CP in yrs & & \\
\hline$<30$ & $4.59(1.15-18.34)$ & $0.03^{*}$ \\
\hline $30-50$ & $1.93(0.48-7.80)$ & 0.36 \\
\hline$>50$ & 1 &
\end{tabular}

The ORs of categorical variables represent comparisons with patients with no risk factor.

${ }^{*} p<0.05$ for difference between nonresorbed implant group and clinical bone flap resorption group.

\section{Strengths and Weaknesses}

The strengths of this study include a relatively large patient population in a multicenter setting. The cohort was large enough in size to demonstrate the most important factors affecting the outcome of $\mathrm{CP}$, and the follow-up period was relatively long. The overall complication and $\mathrm{CP}$ removal rates in our patients were $39.6 \%$ and $19.3 \%$, respectively, both of which are consistent with the figures reported in the current literature. . $^{3,10,22,29,37,43,47}$ The patient series presented here was nonselected, as it comprised all $\mathrm{CP}$ patients from the 3 hospital districts - all of the districts' CPs were performed in these hospitals, and all patients with postoperative complications were referred to one of the 3 centers. Thus, no patients or complications were lost for follow-up, which is not the case in most hospital-based series. This might have slightly increased the prevalence of complications and the percentage of patients requiring bone flap removal.

The best method for studying surgical outcomes is a controlled prospective trial, but this is impossible to arrange in the case of $\mathrm{CP}$ for ethical reasons. All of our patients had indications for CP, and they were not randomizable in terms of reconstruction. Even with this multicenter setting, it would take more than 10 years to gather a population as large as this one, and treatment protocols could change over such a period, which they did not during the period studied here. It is still a possibility that the hospitals may have differed in their treatment protocols and that this may have affected the outcomes. The weakness of using lateral 2D scout images in evaluating the bone flap size is the underestimation caused by the skull curvature, especially near the vertex. Also, most CPs in Finland are performed in patients younger than 65 years, which may have skewed the results somewhat.

\section{Conclusions}

Cranioplasty is associated with a notable burden of postoperative complications and subsequent reoperations. This large, multicenter series demonstrated an increased risk of complications leading to autologous $\mathrm{CP}$ removal 
among cigarette-smoking patients and patients younger than 45 years. We recommend that physicians extensively inform their patients on the pronounced risks of smoking before CP. Patients younger than 30 years had a significantly increased risk of BFR, leading to flap removal or reoperation. The role of DM as a risk factor for a poor $\mathrm{CP}$ outcome requires further evaluation, as the worldwide prevalence of diabetes is on the rise.

\section{Acknowledgments}

Dr. Posti is financially supported by Government's Special Financial Transfer tied to academic research in Health Sciences (Finland) and the Emil Aaltonen Foundation.

We thank Kalle Aitasalo, Jaakko Rinne, Ville Vuorinen, and Timo Koivisto for collaborating in the FiNCIR project.

\section{References}

1. Aaron S, Alexander M, Moorthy RK, Mani S, Mathew V, Patil AK, et al: Decompressive craniectomy in cerebral venous thrombosis: a single centre experience. J Neurol Neurosurg Psychiatry 84:995-1000, 2013

2. Bhaskar IP, Yusheng L, Zheng M, Lee GYF: Autogenous skull flaps stored frozen for more than 6 months: do they remain viable? J Clin Neurosci 18:1690-1693, 2011

3. Brommeland T, Rydning PN, Pripp AH, Helseth E: Cranioplasty complications and risk factors associated with bone flap resorption. Scand J Trauma Resusc Emerg Med 23:75, 2015

4. Chang V, Hartzfeld P, Langlois M, Mahmood A, Seyfried D: Outcomes of cranial repair after craniectomy. J Neurosurg 112:1120-1124, 2010

5. Coelho F, Oliveira AM, Paiva WS, Freire FR, Calado VT, Amorim RL, et al: Comprehensive cognitive and cerebral hemodynamic evaluation after cranioplasty. Neuropsychiatr Dis Treat 10:695-701, 2014

6. Di Stefano C, Rinaldesi ML, Quinquinio C, Ridolfi C, Vallasciani M, Sturiale C, et al: Neuropsychological changes and cranioplasty: a group analysis. Brain Inj 30:164-171, 2016

7. Dünisch P, Walter J, Sakr Y, Kalff R, Waschke A, Ewald C: Risk factors of aseptic bone resorption: a study after autologous bone flap reinsertion due to decompressive craniotomy. J Neurosurg 118:1141-1147, 2013

8. Frisch A, Chandra P, Smiley D, Peng L, Rizzo M, Gatcliffe C, et al: Prevalence and clinical outcome of hyperglycemia in the perioperative period in noncardiac surgery. Diabetes Care 33:1783-1788, 2010

9. Fung C, Murek M, Z'Graggen WJ, Krähenbühl AK, Gautschi OP, Schucht P, et al: Decompressive hemicraniectomy in patients with supratentorial intracerebral hemorrhage. Stroke 43:3207-3211, 2012

10. Gooch MR, Gin GE, Kenning TJ, German JW: Complications of cranioplasty following decompressive craniectomy: analysis of 62 cases. Neurosurg Focus 26(6):E9, 2009

11. Honeybul S, Janzen C, Kruger K, Ho KM: The impact of cranioplasty on neurological function. Br J Neurosurg 27:636-641, 2013

12. Honeybul S, Morrison DA, Ho KM, Lind CRP, Geelhoed E: A randomized controlled trial comparing autologous cranioplasty with custom-made titanium cranioplasty. J Neurosurg 126:81-90, 2017

13. Hutchinson PJ, Kolias AG, Timofeev IS, Corteen EA, Czosnyka M, Timothy J, et al: Trial of decompressive craniectomy for traumatic intracranial hypertension. N Engl J Med 375:1119-1130, 2016

14. Jensen JA, Goodson WH, Hopf HW, Hunt TK: Cigarette smoking decreases tissue oxygen. Arch Surg 126:1131-1134, 1991
15. Kanatani M, Sugimoto T, Kanzawa M, Yano S, Chihara K: High extracellular calcium inhibits osteoclast-like cell formation by directly acting on the calcium-sensing receptor existing in osteoclast precursor cells. Biochem Biophys Res Commun 261:144-148, 1999

16. Khullar D, Maa J: The impact of smoking on surgical outcomes. J Am Coll Surg 215:418-426, 2012

17. Klinger DR, Madden C, Beshay J, White J, Gambrell K, Rickert K: Autologous and acrylic cranioplasty: a review of 10 years and 258 cases. World Neurosurg 82:e525-e530, 2014

18. Korhonen TK, Salokorpi N, Niinimäki J, Serlo W, Lehenkari P, Tetri S: Quantitative and qualitative analysis of bone flap resorption in patients undergoing cranioplasty after decompressive craniectomy. J Neurosurg [epub ahead of print February 23, 2018; DOI: 10.3171/2017.8.JNS171857]

19. Kuri M, Nakagawa M, Tanaka H, Hasuo S, Kishi Y: Determination of the duration of preoperative smoking cessation to improve wound healing after head and neck surgery. Anesthesiology 102:892-896, 2005

20. Lau D, Berger MS, Khullar D, Maa J: The impact of smoking on neurosurgical outcomes. J Neurosurg 119:1323-1330, 2013

21. Lee CH, Chung YS, Lee SH, Yang HJ, Son YJ: Analysis of the factors influencing bone graft infection after cranioplasty. J Trauma Acute Care Surg 73:255-260, 2012

22. Li A, Azad TD, Veeravagu A, Bhatti I, Long C, Ratliff JK, et al: Cranioplasty complications and costs: a national population-level analysis using the MarketScan longitudinal database. World Neurosurg 102:209-220, 2017

23. Lindström D, Sadr Azodi O, Wladis A, Tønnesen H, Linder S, Nåsell H, et al: Effects of a perioperative smoking cessation intervention on postoperative complications: a randomized trial. Ann Surg 248:739-745, 2008

24. Lorget F, Kamel S, Mentaverri R, Wattel A, Naassila M, Maamer M, et al: High extracellular calcium concentrations directly stimulate osteoclast apoptosis. Biochem Biophys Res Commun 268:899-903, 2000

25. Malcolm JG, Rindler RS, Chu JK, Grossberg JA, Pradilla G, Ahmad FU: Complications following cranioplasty and relationship to timing: A systematic review and meta-analysis. J Clin Neurosci 33:39-51, 2016

26. Martin KD, Franz B, Kirsch M, Polanski W, von der Hagen M, Schackert G, et al: Autologous bone flap cranioplasty following decompressive craniectomy is combined with a high complication rate in pediatric traumatic brain injury patients. Acta Neurochir (Wien) 156:813-824, 2014

27. Møller AM, Villebro N, Pedersen T, Tønnesen H: Effect of preoperative smoking intervention on postoperative complications: a randomised clinical trial. Lancet 359:114-117, 2002

28. Moreira-Gonzalez A, Jackson IT, Miyawaki T, Barakat K, DiNick V: Clinical outcome in cranioplasty: critical review in long-term follow-up. J Craniofac Surg 14:144-153, 2003

29. Mracek J, Hommerova J, Mork J, Richtr P, Priban V: Complications of cranioplasty using a bone flap sterilised by autoclaving following decompressive craniectomy. Acta Neurochir (Wien) 157:501-506, 2015

30. NCD Risk Factor Collaboration (NCD-RisC): Worldwide trends in diabetes since 1980: a pooled analysis of 751 population-based studies with 4.4 million participants. Lancet 387:1513-1530, 2016

31. Noordzij PG, Boersma E, Schreiner F, Kertai MD, Feringa $\mathrm{HH}$, Dunkelgrun M, et al: Increased preoperative glucose levels are associated with perioperative mortality in patients undergoing noncardiac, nonvascular surgery. Eur J Endocrinol 156:137-142, 2007

32. Oh JH, Zöller JE, Kübler A: A new bone banking technique to maintain osteoblast viability in frozen human iliac cancellous bone. Cryobiology 44:279-287, 2002 
33. Piedra MP, Nemecek AN, Ragel BT: Timing of cranioplasty after decompressive craniectomy for trauma. Surg Neurol Int 5:25, 2014

34. Sahuquillo J, Arikan F: Decompressive craniectomy for the treatment of refractory high intracranial pressure in traumatic brain injury. Cochrane Database Syst Rev (1):CD003983, 2006

35. Schirmer CM, Hoit DA, Malek AM: Decompressive hemicraniectomy for the treatment of intractable intracranial hypertension after aneurysmal subarachnoid hemorrhage. Stroke 38:987-992, 2007

36. Schuss P, Vatter H, Oszvald A, Marquardt G, Imöhl L, Seifert $\mathrm{V}$, et al: Bone flap resorption: risk factors for the development of a long-term complication following cranioplasty after decompressive craniectomy. J Neurotrauma 30:91-95, 2013

37. Schwarz F, Dünisch P, Walter J, Sakr Y, Kalff R, Ewald C: Cranioplasty after decompressive craniectomy: is there a rationale for an initial artificial bone-substitute implant? A single-center experience after 631 procedures. J Neurosurg 124:710-715, 2016

38. Shahid AH, Mohanty M, Singla N, Mittal BR, Gupta SK: The effect of cranioplasty following decompressive craniectomy on cerebral blood perfusion, neurological, and cognitive outcome. J Neurosurg 128:229-235, 2018

39. Shi Y, Warner DO: Surgery as a teachable moment for smoking cessation. Anesthesiology 112:102-107, 2010

40. Silver IA, Murrills RJ, Etherington DJ: Microelectrode studies on the acid microenvironment beneath adherent macrophages and osteoclasts. Exp Cell Res 175:266-276, 1988

41. Silverstein P: Smoking and wound healing. Am J Med 93 (1A):22S-24S, 1992

42. Stieglitz LH, Fung C, Murek M, Fichtner J, Raabe A, Beck $\mathrm{J}$ : What happens to the bone flap? Long-term outcome after reimplantation of cryoconserved bone flaps in a consecutive series of 92 patients. Acta Neurochir (Wien) 157:275-280, 2015

43. Sundseth J, Sundseth A, Berg-Johnsen J, Sorteberg W, Lindegaard KF: Cranioplasty with autologous cryopreserved bone after decompressive craniectomy: complications and risk factors for developing surgical site infection. Acta Neurochir (Wien) 156:805-811, 2014

44. Timofeev I, Santarius T, Kolias AG, Hutchinson PJA: Decompressive craniectomy - operative technique and perioperative care. Adv Tech Stand Neurosurg 38:115-136, 2012
45. Turan A, Mascha EJ, Roberman D, Turner PL, You J, Kurz A, et al: Smoking and perioperative outcomes. Anesthesiology 114:837-846, 2011

46. Vahedi K, Hofmeijer J, Juettler E, Vicaut E, George B, Algra A, et al: Early decompressive surgery in malignant infarction of the middle cerebral artery: a pooled analysis of three randomised controlled trials. Lancet Neurol 6:215-222, 2007

47. Wachter D, Reineke K, Behm T, Rohde V: Cranioplasty after decompressive hemicraniectomy: underestimated surgery-associated complications? Clin Neurol Neurosurg 115:1293-1297, 2013

48. Walcott BP, Kwon CS, Sheth SA, Fehnel CR, Koffie RM, Asaad WF, et al: Predictors of cranioplasty complications in stroke and trauma patients. J Neurosurg 118:757-762, 2013

49. World Health Organization: Obesity: Preventing and Managing the Global Epidemic. WHO Technical Report Series 894. Geneva: World Health Organization, 2000

50. Zanaty M, Chalouhi N, Starke RM, Clark SW, Bovenzi CD, Saigh M, et al: Complications following cranioplasty: incidence and predictors in 348 cases. J Neurosurg 123:182188,2015

\section{Disclosures}

Dr. Serlo: direct stock ownership in Skulle Implants. Vallittu: member of the board and shareholder with Skulle Implants Corp.

\section{Author Contributions}

Conception and design: all authors. Acquisition of data: Korhonen, Tetri, Huttunen, Lindgren, Piitulainen, Posti. Analysis and interpretation of data: all authors. Drafting the article: all authors. Critically revising the article: all authors. Reviewed submitted version of manuscript: all authors. Approved the final version of the manuscript on behalf of all authors: Korhonen. Statistical analysis: Korhonen, Tetri, Posti. Study supervision: Tetri, Serlo, Posti.

\section{Correspondence}

Tommi K. Korhonen: Oulu University Hospital, Oulu, Finland. tommi.korhonen@student.oulu.fi. 